\title{
STUDY OF DIAMETER, DEPTH AND VARIATION OF RELATIVE FLUX DENSITY OF MOON'S CRATERS
}

\author{
D.R. Upadhayay, " A. Khanal, ${ }^{*}$ and S.R. Shahii* \\ *Department of Physics, Amrit Campus, Thamel, Tribhuvan University, Nepal. \\ ${ }^{* *}$ B.P. Koirala Memorial Planetarium, Observatory and Science Museum Development Board, Kirtipur, Kathmandu, \\ Nepal.
}

\begin{abstract}
In this work, we have selected three craters Mutus, Mutus C and Nearch of the satellite Moon. The fits images were taken from Meade 16- inch LX200GPS Schmidt- Cassegrain Telescope on June 20, 2018 from National observatory located at Nagarkot, Nepal. To find the diameter, number of lines were drawn across the craters and distance of them were determined in pixel size from Aladin V 2.5 software. By using shadow length method, the height of two craters (Mutus and Nearch) were determined and compared with the published one. In addition to this, variations of relative flux density, Gaussian trend distribution of flux were studied.
\end{abstract}

Keywords: Lunar; FITS; Craters; Flux

\section{INTRODUCTION}

Moon is the Earth's only natural satellite having different features among which crater is one of the vital lunar feature. Almost $80 \%$ of the lunar surface is covered by craters because of which its study has become an active area of research for the study of different characteristics of moon. In this work, we studied about different parameters like size, diameter, height etc. of different craters of the moon. We take different images of the craters using telescope located at Nagarkot ${ }^{1}$.

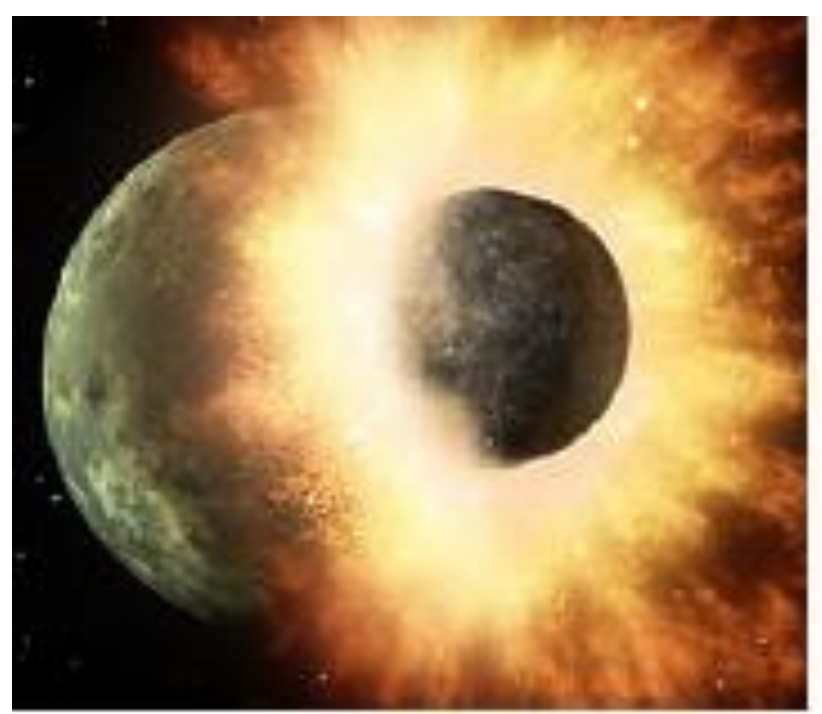

Figure 1: This is an artist's depiction of a catastrophic collision between two celestial bodies; such an impact between the protoEarth and Theia likely formed the Moon ${ }^{2}$.
Table 1 : Facts of the Moon $^{4}$

\begin{tabular}{|l|l|}
\hline Mass & $7.35 \times 10^{22} \mathrm{~kg}$ \\
\hline Density & $3.34 \mathrm{gm} \mathrm{cm}^{-3}$ \\
\hline Diameter & $3,476 \mathrm{~km}$ \\
\hline Average Distance from Earth & $384,400 \mathrm{~km}$ \\
\hline Orbital Period of Revolution & 27.3 Earth Days \\
\hline Synodic Period of Revolution & 29.5 Earth Days \\
\hline Orbital Velocity & $1.08 \mathrm{~km} \mathrm{~s}^{-1}$ \\
\hline Escape Velocity & $2.38 \mathrm{~km} \mathrm{~s}^{-1}$ \\
\hline Strength of gravity on the surface & $1.7 \mathrm{Nkg}^{-1}$ \\
\hline Maximum Distance from Earth & $407,000 \mathrm{~km}^{-}$ \\
\hline $\begin{array}{l}\text { Minimum Distance from } \\
\text { Earth(Perigee) }\end{array}$ & $356,000 \mathrm{~km}$ \\
\hline Albedo & 0.07 \\
\hline
\end{tabular}

\section{Craters}

The word 'Crater' was first adopted by Galileo from the Latin word which means Cup when he viewed the lunar surface with his telescope in $1609 \mathrm{AD}$ and concluded that the Moon is not a perfect sphere but it is fascinated with both mountains and depressions. Most of the lunar surfaces is covered by craters. The Near Side shows the sparse distribution of Craters, seemingly dominated by Maria and Basins whereas the far Side is highly populated with the Craters as large as $1000 \mathrm{~km}$ in diameter ${ }^{3}$.

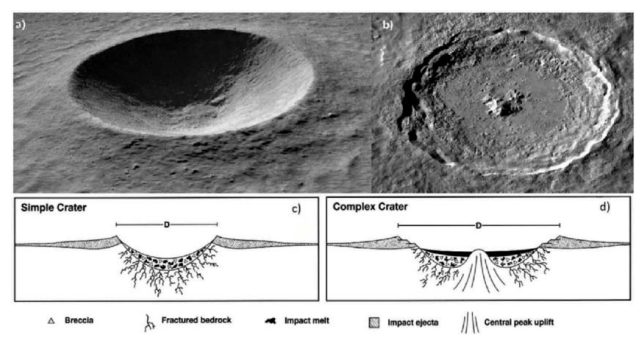

Figure 2. Example of different types of lunar craters, from the simplest one consisting in a single bowl-shape (at the upper left side crater Linné) up to complex craters (at the upper right side crater Tycho). General structure of (a) simple crater and (b) complex crater $^{3}$. 


\section{OBSERVATION}

The observation was taken by the 16-inch LX200 GPS Schmidt-Cannegrain Telescope during the period from March to July 2018 from National Observatory located at Nagarkot, Nepal, East of Kathmandu valley at an elevation of $2115 \mathrm{~m}$ and at latitude $27^{\circ} 41^{\prime} 60^{\prime \prime}$ and longitude $85^{\circ} 31^{\prime} 0^{\prime \prime} 5$

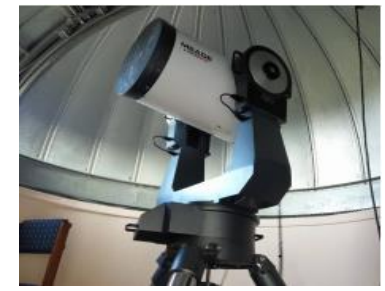

Figure 3. Meade 16" LX200GPS Schmidt- Cassegrain Telescope ${ }^{5}$.

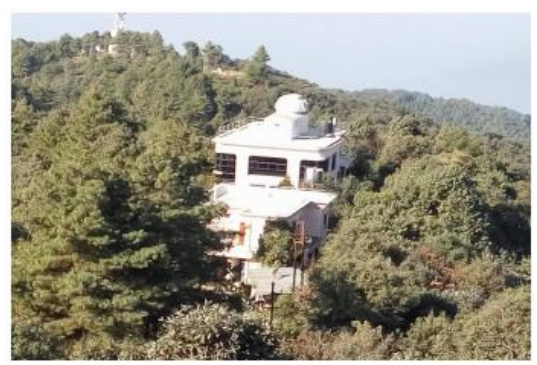

Figure 4: National Observatory, Nagarkot ${ }^{5}$.

\section{METHODOLOGY}

We adopted the following methods in order to study the size of the lunar features. At first craters with good image quality were observed through the eyepiece of 16 " LX200GPS Schmidt-Cassegrain telescope fitted in National Observatory Nagarkot, Nepal. The best FITS images as well as JPEG images of craters showing good surface structure were chosen out of large numbers of images captured by Meade LPI Camera using Auto star suite 3.08 software. With the help of AladinV 2.5, the diameter and height or depth of the craters in pixels were calculated. Thus, obtained diameter and height of the craters in pixels were converted into the standard length using the conversion formula. The official size of craters along with their latitude and longitude were obtained and compared with our calculated values. The published values and the calculated/estimated values were plotted in Origin 5.0 and the variation in them was analyzed. The contour map of flux around craters plotted by using Origin 8.0

Formula used for Determination of Crater Diameter Length or diameter of the Crater ${ }^{8}$,

$\mathrm{L}(\mathrm{km})=\mathrm{cl} \times l \mathrm{~d}_{\text {pixel }}$.

Where $\mathrm{cl}=$ Corrected length

$\ell \mathrm{d}_{\text {pixel }}=$ linear distance covered by 1 pixel $=0.735$ from our observation

$\mathrm{cl}=\mathrm{ul}_{\text {pixel }} \mathrm{x} \mathrm{cf}$....

Where, Tilt correction factor

$(\mathrm{cf})=\frac{1}{\cos (\text { longitude) }+\cos (\text { latitude) }}$

$\mathrm{ul}_{\text {pixel }}=$ Uncorrected diameter or length of crater is calculator by using software aladin V 2.5
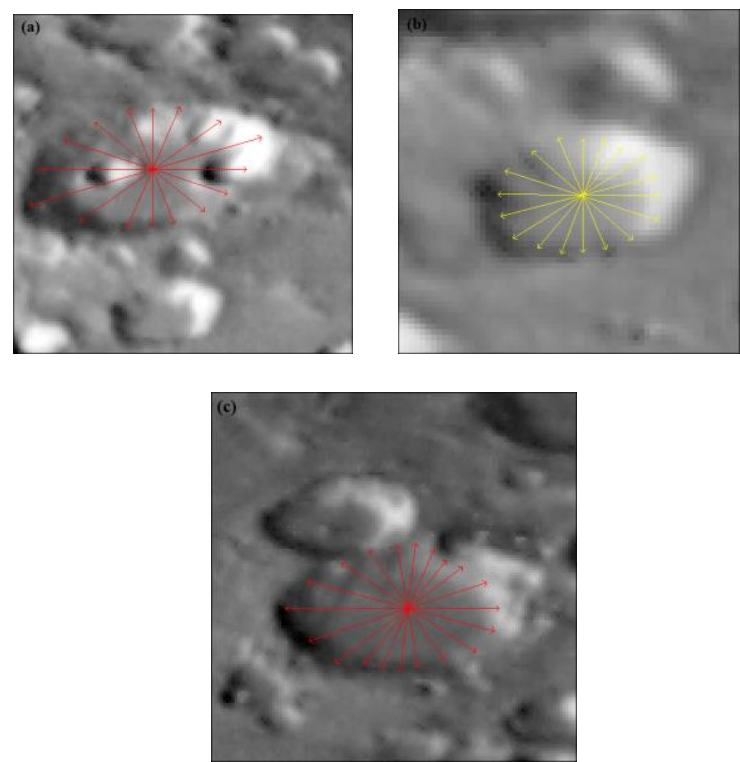

Figure 5: Calculation of craters diameter using Aladin V 2.5.

\section{Formula used for Determination of Crater Height}

The height/depth of the lunar crater can be determined by the simple trigonometry as:

Crater Height $(\mathrm{H})=\tan \theta \times L$.

The value of angle can be determined using formula $<\theta=\arcsin (\mathrm{x})$.

Where, $\mathrm{x}=\sin \left(\mathrm{B}_{\mathrm{o}}\right) \times \sin ($ latitude $)+\cos \left(\mathrm{B}_{\mathrm{o}}\right) \times$ $\cos ($ latitude $) \times \sin \left(\mathrm{C}_{\mathrm{o}}+\right.$ longitude $)$

Terms $B_{0}$ and $C_{0}$ represents the Sub-solar Point

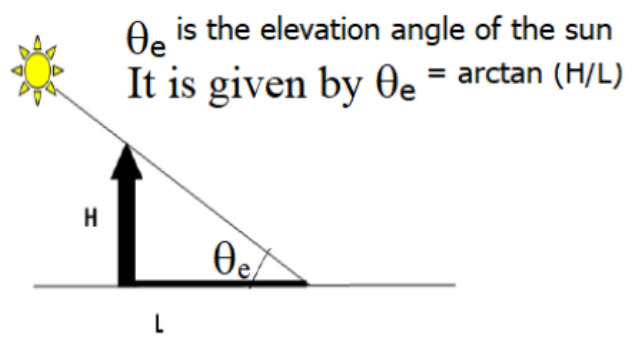

Latitude(Bo) and Solar o-Longitude(Co) respectively ${ }^{9}$.

Figure 6. Diagram showing the angle of elevation of sun on the lunar feature ${ }^{6}$.

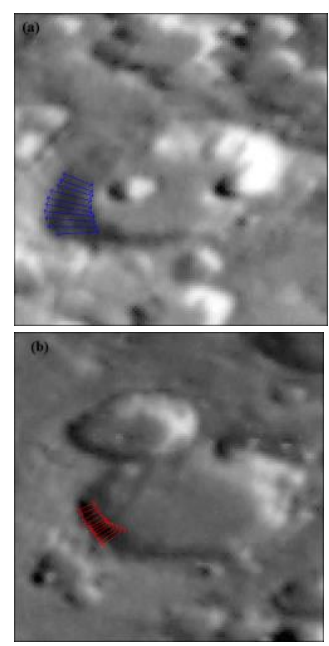

Figure 7. Calculation of craters height using Aladin V 2.5. 


\section{RESULT \& DISCUSSION}

We have presented the result of an image of lunar features containing some selected Crater during our project work. The images were analyzed using AladinV 2.5 software from which diameter and height of selected craters were found out. The software determines the number of pixel formed by the lunar features: rim to rim and shadow of the rim on the surface. Using the formulas mentioned above in equation (1) and (4) respectively we calculated the diameter and height of the crater. The results obtained from the observations and comparison made with the published values is as shown below.

Table 2 : Published ${ }^{7}$ and Calculated Crater's Diameter

\begin{tabular}{|l|c|c|c|c|l|c|}
\hline Name & Longitude & Latitude & $\begin{array}{l}\text { Published } \\
\text { Diameter } \\
(\mathrm{km})\end{array}$ & $\begin{array}{l}\text { Measure } \\
\text { Diameter } \\
(\mathrm{km})\end{array}$ & $\begin{array}{l}\text { Difference } \\
(\% \mathrm{~m}) \\
(\%)\end{array}$ & $\begin{array}{l}\text { Standard } \\
\text { Error } \\
(\mathrm{S} . \mathrm{E})\end{array}$ \\
\hline Mutus & $29.925^{\circ} \mathrm{E}$ & $63.648^{\circ} \mathrm{S}$ & 78 & 116 & $+38(48.71 \%)$ & \\
\hline Mutus C & $27.221^{\circ} \mathrm{E}$ & $61.32^{\circ} \mathrm{S}$ & 32 & 40 & $+8\left(25^{\circ} \%\right)$ & 7.09 \\
\hline Nearch & $39.013^{\circ} \mathrm{E}$ & $58.581^{\circ} \mathrm{S}$ & 76 & 97 & $+21(27.6 \%)$ & \\
\hline
\end{tabular}

From the table we can see that there is difference in the calculated and the published value of the crater's diameter. When we measure the length/diameter of the crater from rim to rim, it can have significant effect on the result and can cause to vary calculated value as much as possible. This variability is due to the foreshortening. The measured length/diameter of the crater in pixel from Aladin2.5 is fully dependent on our accuracy; that can make difference in calculation.

Table 3 : Published $^{7}$ and Calculated Crater height

\begin{tabular}{|l|c|c|c|c|c|c|}
\hline Name & Longitude & Latitude & $\begin{array}{l}\text { Elevation } \\
\text { of sun }\end{array}$ & $\begin{array}{l}\text { Published } \\
\text { Height } \\
(\mathrm{km})\end{array}$ & $\begin{array}{l}\text { Measured } \\
\text { Height } \\
(\mathrm{km})\end{array}$ & $\begin{array}{l}\text { Difference } \\
(\mathrm{km})(\%)\end{array}$ \\
\hline Mutus & $29.925^{\circ} \mathrm{E}$ & $63.648^{\circ} \mathrm{S}$ & $6.2^{\circ}$ & 3.7 & 3.6 & $-0.1(2.7 \%)$ \\
\hline Nearch & $39.013^{\circ} \mathrm{E}$ & $58.581^{\circ} \mathrm{S}$ & $11.476^{\circ}$ & 2.9 & 4.3 & $+1.4(48.2 \%)$ \\
\hline
\end{tabular}

From the 'Table 3' it is seen that there is less difference between the published height and measured height of crater 'Mutus' while there is a significant difference in case of crater 'Nearch'. The difference is of $2.7 \%$ for 'Mutus' while it is of $48.2 \%$ for Nearch. From this it is seen that the difference is greater for that crater whose elevation of $\operatorname{sun}(\theta)$ is greater as $\theta$ for Nearch is $14.48^{\circ}$ and for 'Mutus' is $6.20^{\circ}$.
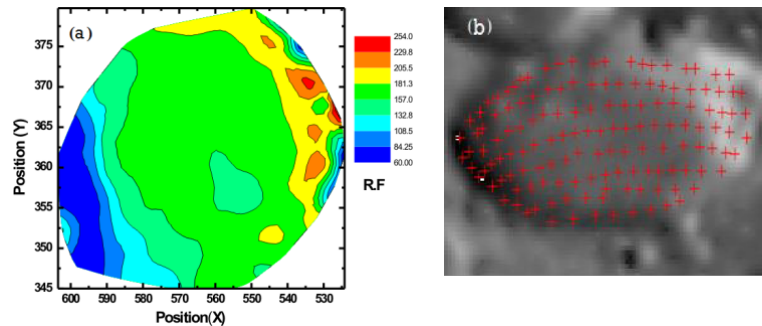

Figure 8: (a) shows the distribution of flux in 'Mutus' crater and figure (b) shows 'Mutus' crater tagged in Aladin V 2.5.

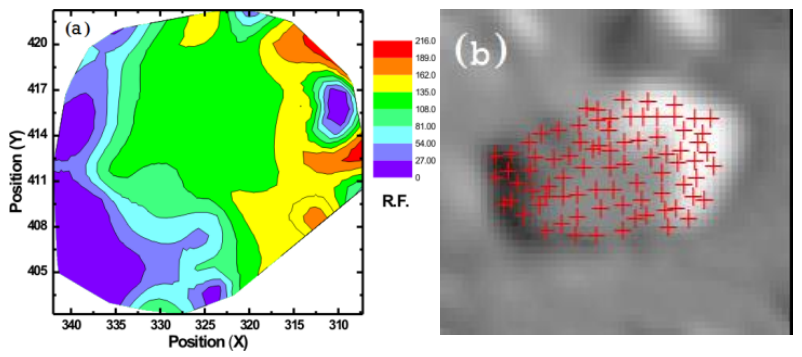

Figure 9: (a) shows the distribution of flux in 'Mutus $C$ ' crater and figure (b) shows 'Mutus $C^{\prime}$ ' crater tagged in Aladin V 2.5.
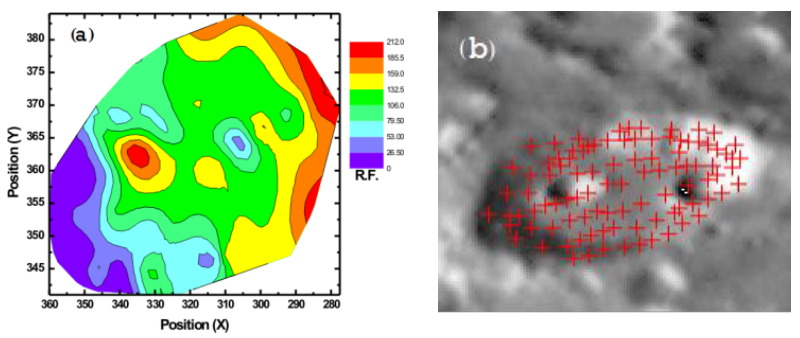

Figure 10: (a) shows the distribution of flux in 'Nearch' crater and figure (b) shows 'Nearch' crater tagged in Aladin V 2.5.

In the above figure, figure 'a' shows the variation of relative flux in different regions of crater 'Mutus'. The region with red colour denotes the region having maximum relative flux whereas the region with violet colour has minimum relative flux.
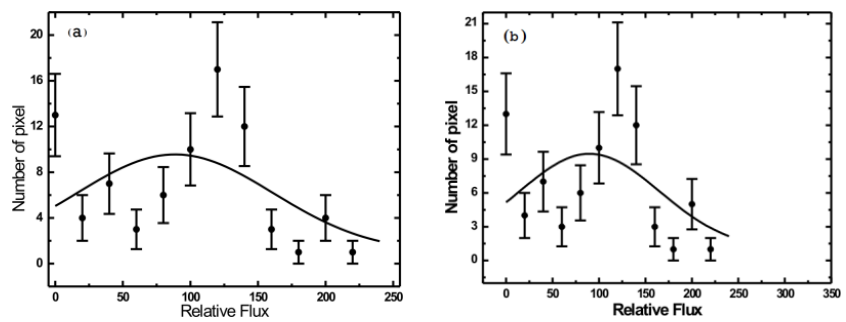

Figure 11: Graphs (a) and (b) shows the Variation Gaussian plots of relative flux with order of pixles of craters 'Mutus' and 'Mutus $C^{\prime}$ ' respectively.
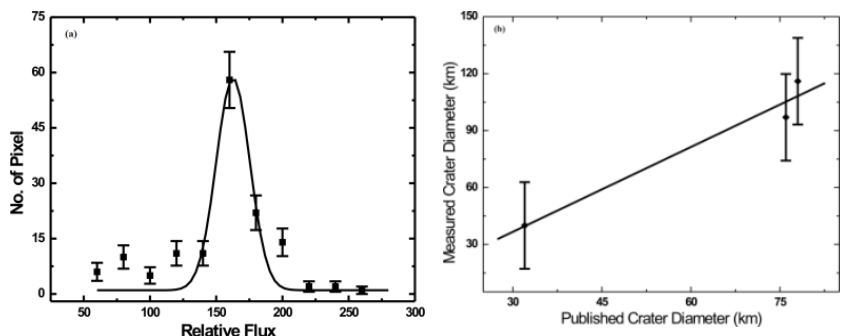

Figure 12: Graphs (a) Variation Gaussian plots of relative flux with order of pixles of craters "Nearch" where as figure (b) shows the variation in Calculated and Published value of diameter of selected Craters.

In all of the above Gaussian diagram as the population of data increases, the maximum permissible error increases. Therefore, we use a $\pm \sqrt{n}$ error bars in the plots where bining has been done. Here ' $n$ ' represents the number of pixels. The Gaussian parameters (area, offset, width and height) are used for the comparison between the various region of interest. The error bars in the Gaussian distribution is simply $\pm \sqrt{n}$ where, $\mathrm{n}$ is the number of data. In figure11, both the nature of curve is not Gaussian which signifies that the flux density over the craters 
'Mutus' and 'Mutus $\mathrm{C}$ ' is anisotropic or polytropic. There is no homogeneity in the distribution of flux in these two craters. But, in figure 12(a) we can see that the nature of curve is almost Gaussian which means that the distribution of flux over the crater 'Nearch' is homogeneous that is isotropic in nature. It should be noted that the value of relative flux density can be converted into $\mathrm{MJy} / \mathrm{sr}$ when multiplied by a factor $5: 1 \mathrm{x}$ $10^{-9}$. We have $1 \mathrm{MJy} / \mathrm{sr}=1 \times 10^{-20} \mathrm{kgs}^{-2}$.

\section{CONCLUSION}

We calculated rim to rim diameter of these craters and also calculated the height of the two craters by using the shadow length method. Also, we studied the distribution of flux on the selected craters by plotting the contour maps for each craters. We studied the Gaussian trend of distribution of flux with the number of pixels plotting the Gaussian function for each three craters. The following conclusions can be drawn from our observation and measurement of size of craters. As the images taken during this work is not much more clear it can be concluded that good and clear images with suitable image scale is needed for the correct calculation of shadow length and rim to rim diameter.

It results a large variation in measurement of crater's size if there is a small error in the measurement of shadow length and rim to rim diameter. The images of individual craters should be taken properly rather than selecting the craters from the single image that has covered the large area of moon. In this work we have chosen the craters from the single image that has contained many craters. So, this could be one of the reasons for the significant variation in between published and measured values of diameters of craters as the image gets more foreshortened. Another reason of the greater error could be due to the measurements taken when the object was far from the direct line of sight, despite of using the trigonometric principles to counter for foreshortening. As we have studied the distribution of flux in the craters the variation of flux in different regions of craters is shown by the variation of colours in contour maps. Also, in the study of Gaussian trend distribution, the function is seen a bit Gaussian for crater 'Nearch' whereas for other two craters (Mutus and Mutus C) the function is not almost Gaussian. This may be because of the insufficient data of flux that is taken from Aladin V 2.5 and also due to unclear images. To sum up, it can be concluded that measurements of crater's height and diameter from the digital imaging from telescopes are affected selected by various factors like shape of the craters, foreshortening of the images, types of shadow cast on the surface, elevation of the sun over the crater wall.

\section{ACKNOWLEDGEMENTS}

We are thankful to B.P. Koirala Memorial Planetarium, Observatory and Science Museum Development Board and all the staffs for their generous co-operation in carrying the data.

\section{REFERENCES}

1. Aryal, B.,Neupane, H. K. and Shahi, S. R. 2011. Scientific World. 9: 8.

2. www.sci-news.com/space/theory-moons-orbit-04327.html (viewed December 2017).

3. Kenkmann, T., Sturm, S. and Krueger,T. 2014. Geophysical Research Abstract. 16.

4. Wilkinson, J. 2010.The Moon In The Close Up, A Next Generation Astronomer's Guide, Patrick Moore's Practical Series, Springer Heidelberg Dordrecht London New York.

5. https://www.planeta-observatory.gov.np/(Viewed in 2018).

6. Pike, R. J. 1974 Geological Research Letter. 1.

7. Andersson, L. E. and Whitaker, E. A. 1982. NASA Catalogue of Lunar Nomenclature, NASA Reference Publication. 1097.

8. Brockman, A. 2008. Smithsonian Astrophysical Observatory Project.

9. http://www.lunaroccultations.com/rlo/ephemeris.htm (viewed in 2018). 